\title{
Expressão de caracteres de tubérculos em função do tamanho de recipiente usado no cultivo de batata na geração de plântulas
}

\author{
Mario Alvaro Aloisio Verissimo ${ }^{1}$, Arione da Silva Pereira², Sergio Delmar dos Anjos e Silva ${ }^{2}$, Laerte Reis Terres ${ }^{1}$, \\ Vicenti Gonçalves Ney ${ }^{1}$, Giovani Olegario da Silva ${ }^{3}$
}

\section{RESUMO}

No melhoramento genético de batata, para alguns caracteres, é possível eliminar genótipos inferiores já nas gerações iniciais, o que permite reduzir o número de genótipos avaliados a campo, proporcionando redução de custos. $\mathrm{O}$ objetivo deste trabalho foi verificar a influência do tamanho de vaso na expressão de caracteres de tubérculo, em famílias de batata, na geração de plântula. Em casa de vegetação, dez famílias de batata foram avaliadas em dois tamanhos de recipientes, vaso grande $(1 \mathrm{~L})$ e vaso pequeno $(250 \mathrm{ml})$. Os caracteres de tubérculos avaliados foram: cor, aspereza, profundidade de olho, sobrancelha, formato, uniformidade de formato, apontamento, curvatura, achatamento, aparência geral, massa por planta, massa média e número de tubérculos. $\mathrm{O}$ vaso grande proporciona maior expressão da variação genética para os caracteres profundidade de olho, sobrancelha, curvatura, achatamento, aparência geral e todos os componentes de rendimento. As maiores médias de produção de tubérculos em número, tamanho e massa foram obtidas no vaso grande, enquanto o maior coeficiente de variação genético para os caracteres formato, uniformidade de formato e apontamento de tubérculo foi obtido no vaso pequeno.

Palavras-chave: Solanum tuberosum L., seleção precoce, melhoramento genético.

\section{ABSTRACT}

\section{Expression of tuber traits as a function of pot size used to grow potato seedlings}

In potato breeding, the exclusion of inferior genotypes by selection in early generations provides more versatility and cost reduction. The objective of this study was to evaluate the influence of pot size on the expression of tuber traits in potato families grown as seedling generation. Ten potato families were planted in two pot sizes, large $(1 \mathrm{~L})$ and small $(250 \mathrm{ml})$, in the greenhouse. The following tuber traits were evaluated: color, roughness, depth of eye, eyebrow, shape, uniformity of shape, pointing, curvature, flattening, tuber general appearance, total mass per plant, average tuber weight and number of tubers. The larger pot provided greater expression of genetic variation for the depth of eye, eyebrow, curvature, flattening, and tuber general appearance of all yield components. Higher means for tuber number, tuber size and tuber mass were obtained in larger pots, while higher genetic coefficient of variation for tuber shape, uniformity of shape and tuber pointing were observed in the small pots.

Key words: Solanum tuberosum L., early selection, genetic improvement.

Recebido para publicação em 01/11/2011 e aprovado em 06/11/2012.

${ }^{1}$ Engenheiro-Agrônomo. Pós-graduando da Faculdade de Agronomia Eliseu Maciel, Universidade Federal de Pelotas, Avenida Eliseu Maciel, Campus Universitário, Caixa Postal 354, 96010-900, Pelotas, Rio Grande do Sul, Brasil. maaverissimo@gmail.com (autor correspondente); laerte_terres@yahoo.com.br; vicentig@gmail.com

${ }^{2}$ Engenheiro-Agrônomo, Doutor. Embrapa Clima Temperado, BR 392, Km 78, Caixa Postal 403, 93001-970, Pelotas, Rio Grande do Sul, Brasil. arione.pereira@embrapa.br; sergio.anjos@embrapa.br

${ }^{3}$ Engenheiro-Agrônomo, Doutor. Embrapa Hortaliças, Rodovia BR 060, Km 09, Caixa Postal 218, 70359-970, Gama, Distrito Federal, Brasil. giovani.olegario@embrapa.br 


\section{INTRODUÇÃO}

No melhoramento genético de batata, milhares de clones são avaliados para a seleção de genótipos superiores. A possibilidade de eliminar grande parte dos clones indesejáveis já nas gerações iniciais é fundamental para que a avaliação dos clones remanescentes seja realizada com mais critério. Assim, evita-se que eles sejam mantidos nos ensaios de campo, proporcionando redução considerável de custos, por menor uso de insumos, área de plantio e mão de obra (Maris, 1988; Xiong et al., 2002).

Os programas de melhoramento de batata são divididos em diversas fases de seleção (Silva \& Pereira, 2011). Após a realização dos cruzamentos, as sementes botânicas são semeadas em casa de vegetação, para a obtenção da primeira geração (plântula). Na segunda fase, um tubérculo de cada plântula é levado a campo (primeira geração clonal), onde se realizam as primeiras seleções. Nas fases seguintes (gerações clonais), aumenta o número de plantas por parcela e diminui o número de clones a serem avaliados. Por fim, os clones superiores são avaliados em ensaios de rendimento e, posteriormente, nos ensaios de valor de cultivo e uso (VCU).

Via de regra, a seleção, na geração de plântulas, é pouco realizada, pois embora sua viabilidade tenha sido demonstrada por vários autores (Neele \& Louwes, 1989; Love et al., 1997; Silva et al., 2008a; Silva et al., 2008b), existem também estudos que questionam sua eficiência (Brown et al., 1984; Gopal \& Minocha, 1997; Melo et al., 2011). A seleção de genótipos na geração de plântula, quando realizada, procede-se por meio de avaliações dos caracteres de alta herdabilidade, como também para os caracteres componentes da aparência de tubérculo. Geralmente, as plântulas são cultivadas em pequenos recipientes plásticos $(250 \mathrm{ml})$, tendo um ambiente reduzido para o seu desenvolvimento e expressão dos caracteres de tubérculo. Resultados de algumas investigações indicam que a eficiência da seleção, em gerações precoces, é de baixa a muito baixa. No entanto, a utilização de recipientes maiores para o cultivo de plântulas poderia minimizar esses problemas, por proporcionar a produção de tubérculos maiores, facilitando a visualização da expressão dos caracteres (Silva \& Pereira, 2011).

A aparência dos tubérculos de batata é um caráter muito importante no momento da comercialização, por causa das preferências dos consumidores (Pereira \& Daniels, 2003). Assim, segundo Silva et al. (2007a; 2008a), há possibilidade de seleção de famílias, na geração de plântula, para os caracteres componentes da aparência (aspereza, formato, profundidade de olhos, sobrancelha, apontamento, curvatura e achatamento de tubérculo), pois estes possuem alta herdabilidade, sendo que, para o caráter formato do tubérculo, pode-se realizar forte seleção. A seleção precoce, começando na geração de plântula, pode ser uma alternativa viável, possibilitando redução de custo e aumento da frequência de genótipos, com melhores características nas fases seguintes de seleção (Silva et al., 2008b).

A utilização de recipientes maiores vem sendo adotada por alguns programas de melhoramento de batata, como o do INIA (Chile) e da Universidade de Cornell (EUA). Nesses programas, recipientes de um litro, por exemplo, vêm sendo utilizados. E a seleção, quando praticada, visa apenas a eliminar genótipos com tubérculos apresentando defeitos fisiológicos externos (rachaduras, etc) e película indesejável quanto à aspereza e coloração. Nesta estratégia, são utilizados os quatro tubérculos maiores, obtidos de cada plântula, em vez de um na primeira geração clonal, como é normalmente feito na maioria dos programas, aumentando a precisão dos resultados dessa geração (Silva \& Pereira, 2011). Neste sentido, não há informações na literatura quanto à expressão de caracteres de tubérculos de plântulas cultivadas em recipientes de diferentes volumes.

O objetivo deste trabalho foi verificar a influência de dois tamanhos de vasos na expressão de caracteres de tubérculo, em famílias de batata, na geração de plântula.

\section{MATERIAL E MÉTODOS}

As plântulas utilizadas foram originadas de sementes sexuais, obtidas de hibridações controladas entre genitores (cultivares e clones elite), da coleção da Embrapa Clima Temperado (CPACT), no município de Pelotas, RS $\left(31^{\circ} \mathrm{S}, 52^{\circ} \mathrm{W}, 70 \mathrm{~m}\right)$, no cultivo de outono de 2010 . Os genitores foram selecionados com o objetivo de obter cruzamentos contrastantes em relação aos caracteres de interesse ao estudo.

O experimento foi realizado com dez famílias híbridas de batata (Solanum tuberosum L. ssp. tuberosum): Família 1: 2AC-999-263-70 x Caesar; Família 2: White Lady x 2AC-999-263-70; Família 3: PCDAG03-11 x 58.97.1; Família 4: Shepody x 2CRI-1149-1-78; Família 5: White Lady x Cota; Família 6: Chipsona x C1730-7-94; Família 7: White Lady x C1742-8-95; Família 8: White Lady x 2CRI-1149-1-78; Família 9: Atlantic x Eliza e Família 10: C1730-7-94 x Caesar.

Em casa de vegetação, as sementes botânicas das dez famílias foram colocadas para germinar em sementeiras e, quando as plântulas atingiram cerca de $10 \mathrm{~cm}$, aproximadamente aos 30 dias após a semeadura, foram transplantadas para os dois tamanhos de recipiente, contendo substrato vegetal, sendo o vaso pequeno (VP), um copo plástico (pvc) preto de $250 \mathrm{ml}$ de volume $(6 \times 6 \times 7,5 \mathrm{~cm}) \mathrm{e}$, o vaso grande (VG), correspondendo a um saco plástico preto de $1 \mathrm{~L}(8 \times 10 \times 12,5 \mathrm{~cm})$. O experimento foi conduzido em casa de vegetação, sob delineamento experimental de 
blocos ao acaso, em parcelas subdivididas, com três repetições. $\mathrm{O}$ fator família foi alocado nas parcelas e o fator recipiente nas subparcelas. As parcelas foram compostas por uma amostra de 30 plântulas por família, dispostas 15 plântulas em cada subparcela. Os vasos foram espaçados de $10 \mathrm{~cm}$ entre e dentro das linhas.

A colheita foi realizada quando as plantas atingiram a senescência, aproximadamente, aos 75 dias após o transplante. As avaliações foram realizadas logo após a colheita, para os caracteres de tubérculo. Com a atribuição de escala de notas variando de 1 a 9, adaptado de Silva et al. (2007b), foram avaliados: Coloração: 1=branco, 9=amarelo; Aspereza da película: $1=$ reticulada, 9=lisa; Profundidade de olho: $1=$ profundo, 9=raso; Sobrancelha: $1=$ sem sobrancelhas, $9=$ extremamente proeminentes; Formato: $1=$ redondo, 9=alongado; Uniformidade de formato: $1=$ desuniforme, 9= uniforme; Apontamento: 1=extremamente apontados, 9=não apontados; Curvatura: 1=extremamente curvados, 9=não curvados; Achatamento: $1=$ extremamente achatados, 9=cilíndricos; Aparência geral: nota baseada em observação visual, considerando como ideal tubérculos lisos, olhos rasos, sem sobrancelha, cilíndricos, retos e não apontados (1=péssima, 9=excelente). Foram avaliados ainda: Número de tubérculos por planta; Massa de tubérculos por planta (g.planta ${ }^{-1}$ ) e Massa média de tubérculo (g.tubérculo ${ }^{-1}$ ), conforme Figura 1.

Os dados foram submetidos à análise de variância no programa GENES (Cruz, 2006). Quando necessário, o teste de Scott-Knott, a $5 \%$ de probabilidade de erro, foi utilizado para agrupamento de médias das famílias.

\section{RESULTADOS E DISCUSSÃO}

Os resultados das análises de variância são apresentados na Tabela 1. Dos 13 caracteres avaliados, para nove foram verificados efeitos significativos de famílias, sendo eles: profundidade de olho (OLH), sobrancelha (SOB), formato (FOR), uniformidade de formato (UFO), apontamento (APO), curvatura (CUR), número de tubérculos por planta (NTU), massa de tubérculos por planta (MAS) e massa média de tubérculo (MMT). Para os caracteres FOR, NTU, MAS e MMT foi verificada interação significativa entre família e tamanho de vaso. Portanto, para esses caracteres, as famílias não mantêm a mesma classificação nos vasos grandes (VG) e pequenos (VP). Para o fator vaso, foram verificados efeitos significativos para FOR, UFO, APO, CUR, achatamento (ACH), aparência geral (APG), NTU, MAS e MMT. Para os caracteres coloração e aspereza, não foram verificados efeitos significativos, de família e vaso.

Os coeficientes de variação estão de acordo com os encontrados na literatura (Silva et al., 2007b; 2008a) (Tabela 1). A presença de variabilidade genética pode ser confirmada e quantificada pelo coeficiente de variação genética $(\mathrm{CVg})$, para todos os caracteres avaliados. Este coeficiente expressa a magnitude da variação genética em relação à média do caráter.

Estimativas do CVg para ambos os vasos (VG e VP) estão apresentadas na Tabela 2. Verifica-se que no VG, cinco caracteres (SOB, UFO, NTU, MAS e MMT) expressaram CVg maior que $10 \%$ e, para o VP, apenas três
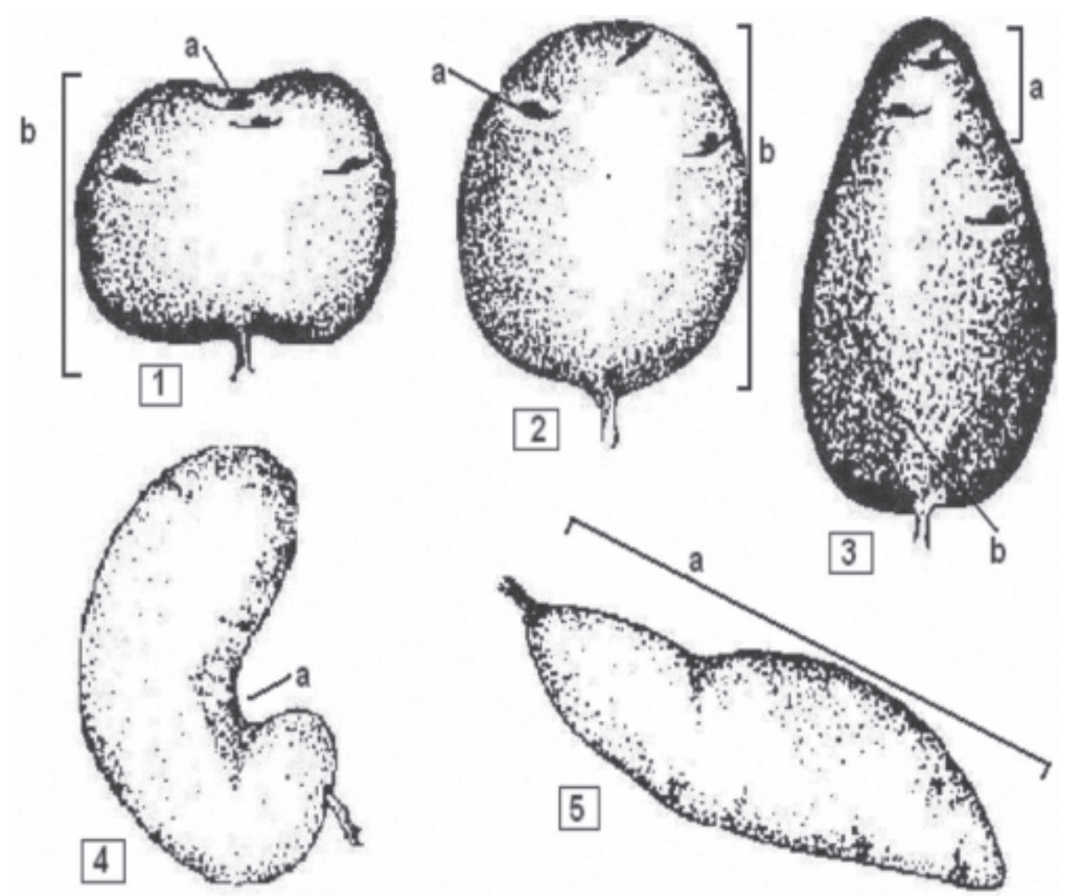

Figura 1. Identificação de caracteres de tubérculos de batata, 1a: profundidade de olhos, 1b: achatamento de tubérculo, 2a: sobrancelha, 2b: tubérculo redondo, 3a: apontamento, 3b: aspereza, 4a: curvatura, 5a: tubérculo alongado (Adaptado de Silva et al., 2008b). 
caracteres (FOR, UFO e MAS). Para os caracteres profundidade de olho (OLH) e SOB, não foram verificadas diferenças significativas entre os vasos. $\mathrm{O}$ VG obteve o maior CVg para ambos os caracteres, com 9,9 e $12,8 \%$, respectivamente, o que indica a maior expressão de variação genética no VG.

FOR e UFO apresentaram maior média no VG, porém o CVg foi maior no VP (FOR: 15,1 e 9,3\%; UFO: 12,7 e 11,2\%, VPe VG, respectivamente). Por ocasião da avaliação, verificaram-se muitos clones com tubérculos arredondados no VP, o que resultou em menores médias (Tabela 2).

A média e o $\mathrm{CVg}$ do caráter apontamento (APO) foram menores no VG, com 6,3 de média e 7\% de CVg. No VP, obteve 6,6 de média e $8,8 \%$ de CVg. Para os caracteres curvatura (CUR) e achatamento (ACH), as médias foram superiores no VP, com 7,0 e 6,7, respectivamente. No entanto, o CVg destes caracteres foi bem superior, quando avaliadas no VG, indicando maior variabilidade genética para os caracteres CUR e ACH, com 8,5 e 5,5\%, respectivamente, no VG, e 5,6 e 1,5\%, no VP. Silva et al. (2007b) verificaram que CUR apresentou-se como o caráter mais efetivo, na seleção indireta, para a melhoria da aparência nas gerações de plântula e primeira geração clonal e que o caráter APO, na geração de plântula, deve ser considerado em conjunto com CUR, na seleção para aparência de tubérculo.

A aparência geral (APG) foi superior, no VG, com 4,8 de média e, neste recipiente, foi verificada variação genética de $1,6 \%$, enquanto, no VP, não foi encontrada (CVg nulo). Segundo Maris (1988), a APG é um caráter que apre-

Tabela 1. Resumo da análise de variância para os caracteres de tubérculos de dez famílias de batata produzidos em dois tamanhos de vaso. Caracteres: Coloração (COR); Aspereza (ASP); Profundidade de olho (OLH); Sobrancelha (SOB); Formato (FOR); Uniformidade de formato (UFO); Apontamento (APO); Curvatura (CUR); Achatamento (ACH); Aparência geral (APG); Número de tubérculos por planta (NTU); Massa de tubérculos por planta (MAS); Massa média de tubérculo (MMT). Pelotas-RS, Embrapa Clima Temperado, 2011

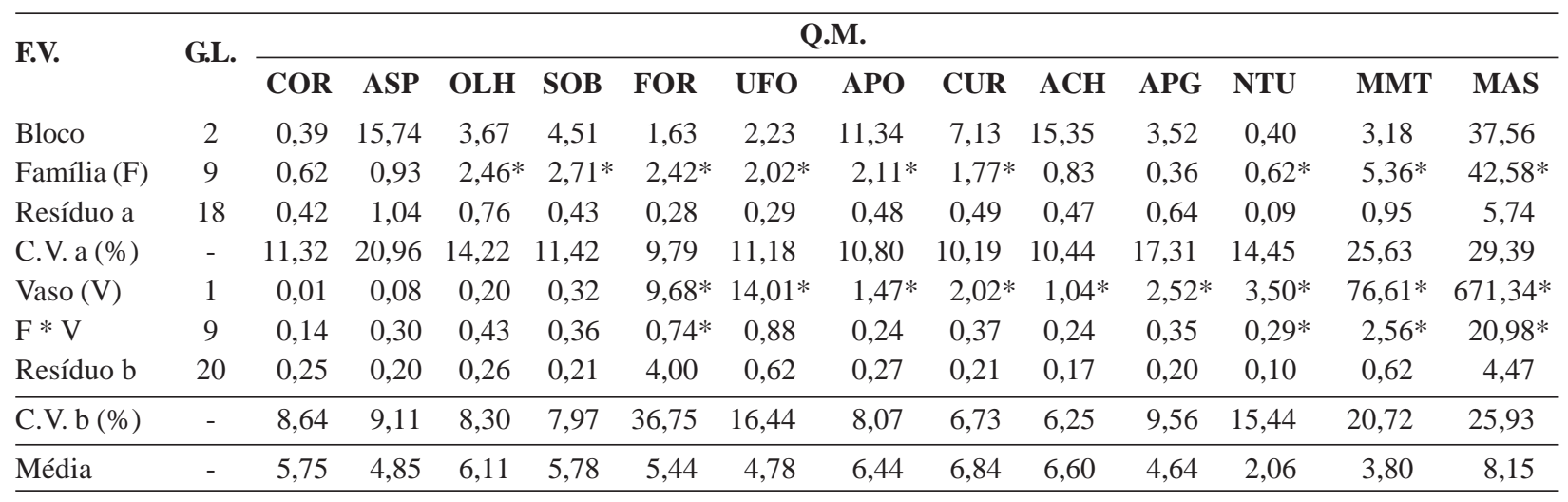

* significativo $(\mathrm{p}<0,05)$ pelo teste $F$.

Tabela 2. Média e coeficiente de variação genético $(\mathrm{CVg}, \%)$ de caracteres de tubérculo de batata, em geração de plântula, cultivada em dois tamanhos de vaso. Pelotas-RS, Embrapa Clima Temperado, 2011

\begin{tabular}{|c|c|c|c|c|}
\hline \multirow[t]{2}{*}{ Caráter $^{1}$} & \multicolumn{2}{|c|}{ Vaso Grande } & \multicolumn{2}{|c|}{ Vaso Pequeno } \\
\hline & Média & CVg & Média & CVg \\
\hline $\mathrm{OLH}^{\text {n.s. }}$ & 6,2 & 9,9 & 6,1 & 8,6 \\
\hline $\mathrm{SOB}^{\text {n.s. }}$ & 5,7 & 12,8 & 5,9 & 9,0 \\
\hline FOR & $5,8 a^{*}$ & 9,3 & $5,0 \mathrm{~b}$ & 15,1 \\
\hline UFO & $5,3 \mathrm{a}$ & 11,2 & $4,3 \mathrm{~b}$ & 12,7 \\
\hline APO & $6,3 \mathrm{~b}$ & 7,0 & $6,6 \mathrm{a}$ & 8,8 \\
\hline CUR & $6,7 \mathrm{~b}$ & 8,5 & $7,0 \mathrm{a}$ & 5,6 \\
\hline $\mathrm{ACH}$ & $6,5 \mathrm{~b}$ & 5,5 & $6,7 \mathrm{a}$ & 1,5 \\
\hline APG & $4,8 \mathrm{a}$ & 1,6 & $4,4 \mathrm{~b}$ & - \\
\hline NTU & $2,3 \mathrm{a}$ & 19,9 & $1,8 \mathrm{~b}$ & 9,5 \\
\hline MAS & $11,5 \mathrm{a}$ & 35,9 & $4,8 \mathrm{~b}$ & 22,6 \\
\hline MMT & $4,9 \mathrm{a}$ & 29,4 & $2,7 \mathrm{~b}$ & 6,3 \\
\hline
\end{tabular}

${ }^{*}$ Médias seguidas pela mesma letra, na linha, não diferem significativamente entre si pelo teste de $F$ ( $\left.\mathrm{p}<0,05\right)$. ${ }^{\text {n.s. }}$, não significativo pelo teste $F(\mathrm{p}<0,05) .{ }^{1}$ Profundidade de olho $(\mathrm{OLH}): 1=$ profundo, $9=$ raso; Sobrancelha $(\mathrm{SOB}): 1=$ sem sobrancelhas, $9=$ =xtremamente proeminentes; Formato (FOR): 1=redondo, 9=alongado; Uniformidade de formato (UFO): 1= desuniforme, 9= uniforme; Apontamento (APO): 1=extremamente apontados, 9=não apontados; Curvatura (CUR): 1=extremamente curvados, $9=$ =não curvados; Achatamento $(\mathrm{ACH})$ : 1=extremamente achatados, 9=tubérculos não achatados; Aparência geral (APG): 1=péssima, 9=excelente; Número de tubérculos por planta (NTU); Massa de tubérculos por planta, em g.planta-1 (MAS); Massa média de tubérculo (MMT), em g.tubérculo ${ }^{-1}$. 
senta baixa eficiência de seleção em gerações iniciais. Por outro lado, de acordo com Silva et al. (2008b), a seleção para APG pode ser melhorada, aplicando-se a seleção aos seus caracteres componentes.

A variação dos caracteres relacionados com a produção, para os quais foi verificada interação significativa entre família e tamanho do vaso, foi mais evidente no recipiente de maior volume, conforme se pode observar nas estimativas do CVg (Tabelas 2 e 4), em que número (NTU), massa por planta (MAS) e massa média de tubérculo (MMT) apresentaram CVg de 19,9, 35,9 e $29,4 \%$ no VG e 9,5, 22,6 e 6,3\% no VP, respectivamente. Observa-se que os $\mathrm{CVg}$ para estes caracteres foram, em média, 2,2 vezes maiores, no VG, do que no VP. No maior recipiente, as plântulas tiveram maior volume de solo, o que proporcionou tubérculos em maior número, massa e massa média. Desta forma, o VG possibilitou maior expressão dos caracteres de produção e, consequentemente, obter melhores estimativas da variabilidade genética existente entre as famílias. Segundo Maris (1988), o efeito da seleção para massa de tubérculos proporciona evidente acréscimo na frequência de plantas com maior massa.

Para os caracteres relacionados com a aparência dos tubérculos, para os quais não foi observada interação significativa entre famílias e tamanho do recipiente, as médias e CVg são apresentadas na Tabela 3. A família 2 apresentou os maiores $\mathrm{CVg}$ para os caracteres profundidade de olho (OLH) e sobrancelha (SOB); no entanto, apresentou a menor média $(4,8)$ para o último, o que indica sobrancelha mais saliente para essa família. Mesmo assim, a família 2 possui potencial para seleção, conforme se verifica pelo alto valor de CVg (10,2\%). Dentre as famílias que apresentaram a maior média para o caráter profundidade de olho $(\mathrm{OLH})$, somente na fa- mília 5, foi detectada variação genética, com CVg acima de zero $(9,8 \%)$. Assim, além de esta família apresentar boa aparência em relação ao caráter OLH, mostra-se com razoável variabilidade genética, com potencial para seleção.

A uniformidade de formato (UFO) foi o caráter para o qual se observou maior número de famílias com a expressão de variabilidade genética, o que pode ser verificado pelos valores de CVg (Tabela 3). Apenas nas famílias 8 e 10, não foi detectada variação genética. As famílias 5, 7 e 10 apresentaram médias estatisticamente inferiores às das demais famílias e, dentre essas, apenas a família 5 apresentou alto CVg $(22,4 \%)$. A família 9, do grupo de médias superiores, apresentou o maior $\mathrm{CVg}(28,4 \%)$, indicando alto potencial de seleção para esse caráter. Destacam-se, também, no grupo de médias superiores, as famílias 3 e 6, que apresentaram CVg de 20,9\% e 25,7\%, respectivamente.

Para apontamento (APO), as famílias com maior média foram 3, 5, 6, 7 e 9, constituindo o grupo superior em relação a este caráter. Dessas famílias, a que apresentou o maior valor de $\mathrm{CVg}$ foi a família 3 (7,4\%). A família 4 ficou no grupo de menor média; entretanto, apresentou o maior CVg (10,8\%).

Para o caráter curvatura (CUR), o CVg foi detectado somente em relação às famílias 1, 3, 4 e 10, com 9,9, 7,4, 14,3 e $0,9 \%$, respectivamente. A família 3 apresentou maior média para CUR, com 7,2, enquanto as demais famílias enquadraram-se no grupo de menor média. A família 4 foi a que obteve maior CVg $(14,3 \%)$.

Para os caracteres achatamento $(\mathrm{ACH})$ e aparência geral (APG), as famílias não diferiram significativamente entre si, na geração de plântula, concordando com os dados de Maris (1988) e Tai \& Young (1984). No entanto, discordam dos dados de Silva et al. (2007a) e Gopal (1997), os quais verificaram diferenças para estes caracteres. Ain-

Tabela 3. Média e coeficiente de variação genético $(\mathrm{CVg}, \%)$ de caracteres de tubérculo de dez famílias de batata, em geração de plântula. Pelotas-RS, Embrapa Clima Temperado, 2011

\begin{tabular}{|c|c|c|c|c|c|c|c|c|c|c|c|c|c|c|}
\hline \multirow{2}{*}{ Família } & \multicolumn{2}{|c|}{ OLH $^{1}$} & \multicolumn{2}{|c|}{ SOB } & \multicolumn{2}{|c|}{ UFO } & \multicolumn{2}{|c|}{ APO } & \multicolumn{2}{|c|}{ CUR } & \multicolumn{2}{|c|}{$\mathrm{ACH}$} & \multicolumn{2}{|c|}{ APG } \\
\hline & Média & $\mathrm{CVg}$ & Média & $\mathrm{CVg}$ & Média & $\mathrm{CVg}$ & Média & $\mathrm{CVg}$ & Média & $\mathrm{CVg}$ & Média & $\mathrm{CVg}$ & Média & $\mathrm{CVg}$ \\
\hline 1 & $5,8 \mathrm{~b}$ & 4,5 & $5,2 \mathrm{~b}$ & 0 & $5,4 \mathrm{a}$ & 7,9 & $5,9 \mathrm{~b}$ & 5,4 & $6,4 \mathrm{~b}$ & 9,9 & $6,2 \mathrm{n}, \mathrm{s}$, & 6,7 & $4,4 \mathrm{n}, \mathrm{s}$, & 0 \\
\hline 2 & $5,6 \mathrm{~b}$ & 11,9 & $4,8 \mathrm{~b}$ & 10,2 & $5,3 \mathrm{a}$ & 12,7 & $6,3 \mathrm{~b}$ & 0 & $6,8 \mathrm{~b}$ & 0 & 6,4 & 0 & 4,6 & 3,1 \\
\hline 3 & $6,6 \mathrm{a}$ & 0 & $6,0 \mathrm{a}$ & 4,1 & $5,1 \mathrm{a}$ & 20,9 & $6,8 \mathrm{a}$ & 7,4 & $7,2 \mathrm{a}$ & 7,4 & 7,1 & 7,3 & 5,0 & 8,6 \\
\hline 4 & $5,1 \mathrm{~b}$ & 0 & $4,9 \mathrm{~b}$ & 5,7 & $5,0 \mathrm{a}$ & 4,8 & $5,6 \mathrm{~b}$ & 10,8 & $6,0 \mathrm{~b}$ & 14,3 & 5,9 & 10,3 & 4,3 & 0 \\
\hline 5 & $7,1 \mathrm{a}$ & 9,8 & $6,6 \mathrm{a}$ & 0 & $3,8 \mathrm{~b}$ & 22,4 & $7,0 \mathrm{a}$ & 4,2 & $7,3 \mathrm{a}$ & 0 & 6,8 & 0 & 4,7 & 1,5 \\
\hline 6 & $5,8 \mathrm{~b}$ & 0 & $5,3 \mathrm{~b}$ & 4,4 & $4,9 \mathrm{a}$ & 25,7 & $7,1 \mathrm{a}$ & 3,4 & $7,4 \mathrm{a}$ & 0 & 6,7 & 0 & 4,5 & 15,1 \\
\hline 7 & $6,6 \mathrm{a}$ & 0 & $6,3 \mathrm{a}$ & 0 & $4,4 \mathrm{~b}$ & 3,2 & $6,9 \mathrm{a}$ & 4,1 & $7,3 \mathrm{a}$ & 0 & 6,9 & 0 & 4,6 & 0 \\
\hline 8 & $5,7 \mathrm{~b}$ & 0 & $6,0 \mathrm{a}$ & 6,1 & $5,2 \mathrm{a}$ & 0 & $5,6 \mathrm{~b}$ & 0 & $6,1 \mathrm{~b}$ & 0 & 6,3 & 0 & 4,9 & 10,0 \\
\hline 9 & $6,0 \mathrm{~b}$ & 0 & $6,2 \mathrm{a}$ & 0 & $5,0 \mathrm{a}$ & 28,4 & $7,0 \mathrm{a}$ & 0 & $7,4 \mathrm{a}$ & 0 & 6,8 & 0 & 4,6 & 14,7 \\
\hline 10 & $6,9 \mathrm{a}$ & 0 & $6,5 \mathrm{a}$ & 4,5 & $3,8 \mathrm{~b}$ & 0 & $6,2 \mathrm{~b}$ & 0 & $6,6 \mathrm{~b}$ & 0,9 & 6,8 & 0 & 4,9 & 0 \\
\hline
\end{tabular}

* Médias seguidas pela mesma letra não diferem significativamente entre si pelo teste de Scott-Knott. n.s., não significativo pelo teste $F$ (p<0,05).

${ }^{1}$ Profundidade de olho $(\mathrm{OLH})$ : 1=profundo, 9=raso; Sobrancelha (SOB): 1=sem sobrancelhas, $9=$ extremamente proeminentes; Uniformidade de formato (UFO): $1=$ desuniforme, $9=$ uniforme; Apontamento (APO): 1=extremamente apontados, $9=$ não apontados; Curvatura (CUR): 1=extremamente curvados, $9=$ não curvados; Achatamento (ACH): $1=$ extremamente achatados, $9=$ tubérculos não achatados; Aparência geral (APG): 1=péssima, 9=excelente. 
da assim, foi possível detectar CVg para as famílias 1,3 e 4, quanto ao caráter $\mathrm{ACH}$, e, para as famílias 2, 3, 5, 6, 8 e 9, em relação ao caráter APG.

As famílias que apresentaram maior média de massa por planta (MAS) foram 1, 2, 3, 4 e 6. Igualmente, essas famílias apresentaram CVg superior a 50\%. Para as famílias 2 e 6 , a MAS foi superior a 17 g planta $^{-1}$ no VG (Tabela 4) e a massa média de tubérculo (MMT) foi de 5,7 e 7,1 g tubérculo $^{-1}$, respectivamente, com CVg de 45 e $59 \%$. Portanto, essas famílias, além de apresentarem médias elevadas para os caracteres de produção, também apresentaram as maiores estimativas de variabilidade genética.
A seleção precoce para alguns caracteres na geração de plântula pode economizar recursos consideráveis e aumentar a frequência de genótipos com melhores características, nas fases posteriores de seleção (Neele \& Louwes, 1989; Love et al., 1997; Silva et al., 2007a; Silva et al., 2007b; Silva \& Pereira, 2011); entretanto, não tem sido aplicada na geração de plântula, em função do questionamento de sua eficiência (Brown et al., 1984; Gopal \& Minocha, 1997; Melo et al., 2011). Os resultados encontrados com este trabalho apontam considerável melhoria da expressão da variação genética para os caracteres que compõe a aparência de tubérculo.

Tabela 4. Média e coeficiente de variação genético $(\mathrm{CVg}, \%)$ para os caracteres formato e componentes do rendimento de dez famílias de batata, em geração de plântula, cultivadas em dois tamanhos de vaso. Pelotas-RS, Embrapa Clima Temperado, 2011

\begin{tabular}{|c|c|c|c|c|c|c|c|c|c|c|c|c|}
\hline \multirow{3}{*}{ Família } & \multicolumn{3}{|c|}{ FOR $^{1}$} & \multicolumn{3}{|c|}{ MAS } & \multicolumn{3}{|c|}{ NTU } & \multicolumn{3}{|c|}{ MMT } \\
\hline & \multicolumn{2}{|c|}{ Média } & \multirow{2}{*}{ CVg } & \multicolumn{2}{|c|}{ Média } & \multirow{2}{*}{ CVg } & \multicolumn{2}{|c|}{ Média } & \multirow{2}{*}{ CVg } & \multicolumn{2}{|c|}{ Média } & \multirow{2}{*}{$\mathrm{CVg}$} \\
\hline & $\mathbf{V G}^{2}$ & VP & & VG & $\mathbf{V P}$ & & VG & VP & & VG & VP & \\
\hline 1 & $6,2 \mathrm{~A} \mathrm{a}$ & $5,9 \mathrm{~A} \mathrm{a}$ & 0 & $14,4 \mathrm{~A} \mathrm{a}$ & $5,9 \mathrm{~B} \mathrm{a}$ & 54,7 & $3,2 \mathrm{~A} \mathrm{a}$ & $2,1 \mathrm{~B} \mathrm{a}$ & 27,3 & $4,5 \mathrm{~A} \mathrm{~b}$ & $2,9 \mathrm{~B} \mathrm{a}$ & 29,3 \\
\hline 2 & $6,0 \mathrm{~A} \mathrm{a}$ & $6,4 \mathrm{~A}$ a & 0 & $17,1 \mathrm{~A} \mathrm{a}$ & $5,9 \mathrm{~B} \mathrm{a}$ & 67,8 & $3,1 \mathrm{~A} \mathrm{a}$ & $2,1 \mathrm{~B} \mathrm{a}$ & 26,0 & $5,7 \mathrm{~A} \mathrm{a}$ & $2,8 \mathrm{~B} \mathrm{a}$ & 45,2 \\
\hline 3 & $5,8 \mathrm{~A} \mathrm{a}$ & $4,5 \mathrm{~B} \mathrm{~b}$ & 17,5 & $14,0 \mathrm{~A} \mathrm{a}$ & $3,8 \mathrm{~B} \mathrm{a}$ & 80,7 & $2,3 \mathrm{~A} \mathrm{~b}$ & $1,6 \mathrm{~B} \mathrm{a}$ & 24,3 & $6,1 \mathrm{~A} \mathrm{a}$ & $2,4 \mathrm{~B}$ a & 62,3 \\
\hline 4 & $6,9 \mathrm{~A} \mathrm{a}$ & $4,9 \mathrm{~B} \mathrm{~b}$ & 24,0 & $11,6 \mathrm{~A} \mathrm{~b}$ & $5,4 \mathrm{~B} \mathrm{a}$ & 50,6 & $1,8 \mathrm{~A} \mathrm{~b}$ & $1,9 \mathrm{~A} \mathrm{a}$ & 0 & $6,5 \mathrm{~A} \mathrm{a}$ & $2,9 \mathrm{~B} \mathrm{a}$ & 53,2 \\
\hline 5 & $5,8 \mathrm{~A} \mathrm{a}$ & $4,4 \mathrm{~B} \mathrm{~b}$ & 18,2 & $7,1 \mathrm{~A} \mathrm{c}$ & $3,2 \mathrm{~B} \mathrm{a}$ & 41,1 & $2,0 \mathrm{~A} \mathrm{~b}$ & $1,5 \mathrm{~B} \mathrm{a}$ & 22,6 & $3,4 \mathrm{Acc}$ & $2,3 \mathrm{~A} \mathrm{a}$ & 0 \\
\hline 6 & $5,7 \mathrm{~A} \mathrm{a}$ & $4,4 \mathrm{~B} \mathrm{~b}$ & 16,8 & $17,4 \mathrm{~A} \mathrm{a}$ & $5,0 \mathrm{~B} \mathrm{a}$ & 77,1 & $2,4 \mathrm{~A} \mathrm{~b}$ & $1,7 \mathrm{~B} \mathrm{a}$ & 23,2 & $7,1 \mathrm{~A} \mathrm{a}$ & $2,9 \mathrm{~B} \mathrm{a}$ & 59,1 \\
\hline 7 & $5,5 \mathrm{~A} \mathrm{a}$ & $4,9 \mathrm{~A} \mathrm{~b}$ & 6,0 & $7,2 \mathrm{~A} \mathrm{c}$ & $3,8 \mathrm{~A} \mathrm{a}$ & 43,5 & $2,1 \mathrm{~A} \mathrm{~b}$ & $1,8 \mathrm{~A} \mathrm{a}$ & 8,3 & $3,4 \mathrm{Ac}$ & $2,1 \mathrm{~A} \mathrm{a}$ & 31,2 \\
\hline 8 & $6,4 \mathrm{~A} \mathrm{a}$ & $5,7 \mathrm{~A} \mathrm{a}$ & 7,3 & $11,8 \mathrm{~A} \mathrm{~b}$ & $6,6 \mathrm{~B} \mathrm{a}$ & 38,3 & $1,9 \mathrm{~A} \mathrm{~b}$ & $2,0 \mathrm{~A} \mathrm{a}$ & 0 & $6,0 \mathrm{~A} \mathrm{a}$ & $3,4 \mathrm{~B}$ a & 39,1 \\
\hline 9 & $4,5 \mathrm{~A} \mathrm{~b}$ & $3,8 \mathrm{~A} \mathrm{~b}$ & 10,8 & $10,4 \mathrm{~A} \mathrm{~b}$ & $5,2 \mathrm{~B} \mathrm{a}$ & 45,3 & $2,4 \mathrm{~A} \mathrm{~b}$ & $1,7 \mathrm{~B} \mathrm{a}$ & 21,6 & $4,3 \mathrm{~A} \mathrm{~b}$ & $3,1 \mathrm{~A} \mathrm{a}$ & 22,2 \\
\hline 10 & $5,7 \mathrm{~A} \mathrm{a}$ & $5,5 \mathrm{~A} \mathrm{a}$ & 0 & $4,0 \mathrm{~A} \mathrm{c}$ & $3,2 \mathrm{~B} \mathrm{a}$ & 11,6 & $1,7 \mathrm{~A} \mathrm{~b}$ & $1,8 \mathrm{~A} \mathrm{a}$ & 0 & $2,4 \mathrm{Ac}$ & $2,0 \mathrm{~A} \mathrm{a}$ & 0 \\
\hline Média & $5,8 \mathrm{~A}$ & $5,0 \mathrm{~B}$ & & $11,5 \mathrm{~A}$ & $4,8 \mathrm{~B}$ & & $2,3 \mathrm{~A}$ & $1,8 \mathrm{~B}$ & & $4,9 \mathrm{~A}$ & $2,7 \mathrm{~B}$ & \\
\hline
\end{tabular}

*Médias seguidas pela mesma letra maiúscula, na linha, e minúscula, na coluna, não diferem significativamente entre si pelos testes $F$ e Scott-Knott $(\mathrm{p}<0,05)$, respectivamente. ${ }^{1}$ Formato (FOR): 1=redondo, 9=alongado; Número de tubérculos por planta (NTU); Massa de tubérculos por planta, em g.planta ${ }^{-1}$ (MAS); Massa média de tubérculo (MMT), em g.tubérculo ${ }^{-1}{ }^{2}$ Vaso grande (VG), $1 \mathrm{~L}$; vaso pequeno (VP), $250 \mathrm{ml}$.

\section{CONCLUSÕES}

Na avaliação de batata na fase de plântula, o recipiente de $1 \mathrm{~L}$ proporciona maior expressão dos caracteres profundidade de olho, sobrancelha, curvatura, achatamento, aparência geral e para os componentes de rendimento de tubérculos de batata, número, massa por planta e massa média, enquanto, para os caracteres formato, uniformidade de formato e apontamento de tubérculos de batata, melhores resultados são obtidos no recipiente de $250 \mathrm{ml}$.

\section{AGRADECIMENTOS}

À CAPES, pela concessão de bolsa de estudo, e ao CNPq, pelo suporte financeiro, projeto $\mathrm{n}^{\circ}$ 402059/2008-5.

\section{REFERÊNCIAS}

Brown J, Caligari PDS, Mackay GR \& Swan GEL (1984) The efficiency of visual selection in early generations of potato breeding programme. Annals of Apllied Biology, 110:357-363.
Cruz CD (2006) Programa Genes: Biometria. Viçosa, Editora UFV. $382 \mathrm{p}$.

Gopal J (1997) Progeny selection for agronomic characters in early generations of potato breeding programme. Theorical and Applied Genetics, 95:307-3011.

Gopal J \& Minocha JL (1997) Effectiveness of selection at microtuber crop level in potato. Plant Breeding, 116:293295.

Love SL, Werner BK \& Pavek JJ (1997) Selection for individual traits in the early generations of a potato breeding program dedicated to producing cultivars with tubers having long shape and russet skin. American Potato Journal, 74:199-213.

Maris B (1988) Correlations within and between characters and generations as a measure for the early generation selection in potato breeding. Euphytica, 37:205-224.

Melo DS, Brasil CA, Pinto P, Peixouto LS, Neder DG \& Assis JC (2011) Early selection of full-sib potato families. Ciência e Agrotecnologia, 35:1101-1109.

Neele AEF \& Louwes KM (1989) Early selection for chip quality and dry matter content in potato seedling populations in greenhouse or screenhouse. Potato Research, 32:293-300. 
Pereira AS \& Daniels J (2003) O cultivo da batata na região sul do Brasil. Brasília, Embrapa Informação Tecnológica/Embrapa Clima Temperado. 567p.

Silva GA, Pereira AS, Souza VQ, Carvalho FIF de \& Neto RF (2007a) Parâmetros genéticos em primeiras gerações de seleção em batata (Solanum tuberosum L.). Magistra, 19:98-103.

Silva GO, Pereira AS, Souza VQ, Carvalho FIF \& Neto RF (2007b) Correlações entre caracteres de aparência e rendimento e análise de trilha para aparência de batata. Bragantia, 66:381-388.

Silva GO, Pereira AS, Souza VQ, Carvalho FIF \& Fritsche Neto R (2008a) Seleção para caracteres fenotípicos de tubérculos nas primeiras gerações em batata. Revista Ceres, 55:168-172.
Silva GO, Pereira AS, Souza VQ, Carvalho FIF \& Fritsche Neto R (2008b) Seleção para caracteres componentes de aparência e rendimento de tubérculo em plântulas de batata. Horticultura Brasileira, 26:325-329.

Silva GO \& Pereira AS (2011) Seleção em gerações iniciais para caracteres agronômicos em batata. Horticultura Brasileira, 29:449-455.

Tai GCC \& Young DA (1984) Early generation selection for important agronomic characteristics in a potato breeding population. American Potato Journal, 61:419-434.

Xiong X, Tai GCC \& Seabrook JEA (2002) Effectiveness of selection for quality traits during the early stage in the potato breeding population. Plant Breeding, 121:441-444. 